\title{
Research on Fiscal Expenditure and Tourism Development of Huangshan City: Based on Grey Relational Analysis
}

\author{
Wenhao $\mathrm{Wu}^{1}$ and Huibin $\mathrm{Zhan}{ }^{1}$ \\ ${ }^{1}$ Huangshan University 39 Xihai Rd. 245041 Huangshan, Anhui, China
}

\begin{abstract}
Using grey relational analysis, the impacts of various fiscal expenditure items on local tourism development were detected by employing relevant statistical data from Huangshan City during 2008- 2013. Top five fiscal expenditure items influencing local tourism development, including general public services, education, public security, social security and employment, as well as urban and rural community affairs, were revealed in this analysis. According to the results, expenditure efficiency and its important domains are able to be recognized and verified under current economic and social circumstances. As a result, in order to optimize the expenditure structure, we suggest that financial strengthen, existing economic and geography resource, as well as the requirements of tourism development for tourism demand in the new stage should be combined.
\end{abstract}

Keywords. Fiscal expenditure, tourism development, grey relational analysis, Huangshan City.

\section{Introduction}

Chinese tourism is in transition stage with constant development of self-service, pluralism, popularization and normalization. New features of tourism consumption and demand have emerged in various aspects, causing changes in public needs of tourism. Therefore, government functions should be transformed with adjustment in structure of government expenditure, thus improving the level and quality of tourism in new development context.

Basis of government fiscal function in tourism development is reflected in public goods, externality, intra-generational and inter-generational factors, as well as market failure such as monopoly [1]. In China, financial support for tourism is also closely related to development goals of tourism which should meet the requirements of the rapidly developed economy, society and culture. Since the 1980s, most of the local governments of Chinese provinces, autonomous regions and municipalities have introduced financial support policies in succession to promote tourism development based on the development goals of local tourism industry [2].

Urban tourism attracts comprehensive attentions in recent years. Wang and Pei (2014) established an index system and a grey comprehensive evaluation model to analyze the sustainability of urban tourism [3]. Zhou \& Dong (2014) use similar approach to investigate tourism development of Xinjiang. More specifically [4], He, Chen \& Zhai (2012) examined the correlation between forest tourism and three industrial sectors in Eastern Liaoning from 2000 to 2009 [5], and Liu, Gao \& Xue (2013) evaluated tourism festival activities impact on water environment in DongPing Forest Park $[6]$. 
Further, some scholars exhibit more interests on the relationship between fiscal expenditure and tourism development. Ishikawa and Fukushige (2009) examined the impact of fiscal expenditure and the number of tourists on per capita taxable income in Japanese remote islands, and find that the former exhibit positive significant relationship while the latter not [7]. Avramescu \& Baldan (2011) use degree of taxation, interest rate and exchange rate to analyzes the impact of Romania`s main fiscal and monetary measures on the development of the tourism sector, results showing that negative relationship existed and other financial solutions can boost Romanian tourism [8]. Feliziani \& Monni (2013) analyzed the role of fiscal policies in the tourist sector, and find that governance is one of the major causes of weakness [9].

Based on previous researches, our analysis focus on the following questions: what kind of financial supports does tourism development need? How to promote and adapt to transformation and structural adjustment of tourism industry at this stage through financial expenditure? The domains and tourist effects are different for the influence of different items of fiscal expenditure. It is very important to understand the different impacts brought by different components of tourism expenditure, which is a critical step for further improvement of efficiency of fiscal expenditure.

\section{Research methods, index selection and data sources}

\subsection{Research methods}

As a complex and integrated system, tourism system has limited statistic data with greater fluctuation and less typical distribution laws. Thus it is difficult to define all factors of tourism system and mechanism interacted among them. In this context, we regard tourism system as a grey system. To be specific, Grey system theory was first proposed by Chinese scholar Deng Julong in 1982, and had been widely used in social, economic and ecological domains. In the study, grey correlation analysis in gray system theory was employed to quantify the correlation between fiscal expenditure and tourism, revealing the relationship between expenditure and tourism development.

\subsection{Index selection}

\subsubsection{Selection of related indexes for fiscal expenditure}

The main indexes selected to measure fiscal expenditure in Huangshan City include General public services (X1), Public security (X2), Education (X3), Science and technology (X4), Culture, sports and media (X5), Social security and employment (X6), Health care (X7), Environmental protection (X8), Urban and rural community affairs (X9), Agriculture, forestry and water affairs (X10),Transportation (X11), as well as Industrial, commercial and financial affairs (X12).

\subsubsection{Selection of related indexes for tourism development}

There were four first-grade indexes and five second-grade indexes selected to measure tourism development in Huangshan City (See Table 1). The indexes reflect current situations of tourism development in Huangshan City from different aspects. Tourism-related industries were defined based on classification criteria ${ }^{1}$ of the World Tourism Organization [10]. Meanwhile, the availability of data was taken into account.

Table 1. Indexes for tourism development in Huangshan City.

\begin{tabular}{|l|c|}
\hline First-grade indexes & Second-grade indexes \\
\hline Tourist income $\left(\mathrm{Y}_{1}\right)$ & Total tourism income $(\mathrm{Y} 11)$ \\
\cline { 2 - 2 } & Domestic tourism income $\left(\mathrm{Y}_{12}\right)$ \\
\cline { 2 - 2 } & Foreign exchange earnings from tourism $\left(\mathrm{Y}_{13}\right)$ \\
\hline
\end{tabular}

\footnotetext{
${ }^{1}$ According to the classification criteria of the World Tourism Organization, tourism can be divided into total-tourism sector and partial-participation tourism sector.
} 


\begin{tabular}{|c|c|}
\hline \multirow[t]{2}{*}{ Tourist person-time $\left(\mathrm{Y}_{2}\right)$} & Domestic tourist person-time $\left(\mathrm{Y}_{21}\right)$ \\
\hline & Foreign tourist person-time $\left(\mathrm{Y}_{22}\right)$ \\
\hline \multirow[t]{2}{*}{ Tourist person-day $\left(\mathrm{Y}_{3}\right)$} & Domestic tourist person-day $\left(\mathrm{Y}_{31}\right)$ \\
\hline & Foreign tourist person-day $\left(\mathrm{Y}_{32}\right)$ \\
\hline \multirow[t]{8}{*}{ Tourism-related industries $\left(\mathrm{Y}_{4}\right)$} & Transportation, warehousing and postal service $\left(\mathrm{Y}_{41}\right)$ \\
\hline & Wholesale and retail (Y42) \\
\hline & Accommodation and catering (Y43) \\
\hline & Financial industry $\left(\mathrm{Y}_{44}\right)$ \\
\hline & Leasing and business service $\left(\mathrm{Y}_{45}\right)$ \\
\hline & Culture, Sports and Entertainment $\left(\mathrm{Y}_{46}\right)$ \\
\hline & Public Management and Social Organization $\left(\mathrm{Y}_{47}\right)$ \\
\hline & Residents service and other services $\left(\mathrm{Y}_{48}\right)$ \\
\hline
\end{tabular}

\subsection{Data sources}

The data used in this study were extracted from the Statistical Yearbook of Huangshan City from 2008 to 2013 (See Table 2 and 3 ).

\section{Gray relational analysis}

In grey relational theory, determinate factors are selected among multiple factors in the system for comparison. The basic concepts include: the relevance can be judged through the level of similarity between comparison sequence curve and reference sequence curve; the strength and weakness of evaluation objects are analyzed though grey relational degree. Relational degree indicates the correlation among things and factors, which quantitatively describes relative change of things or factors. The main relationship among these factors can be revealed using grey relational analysis with certain methods, exploring important factors affecting target values, thus clarifying the correlation among these factors.

Table 2. Indexes of fiscal expenditure in Huangshan City (Unit: ten thousand RMB).

\begin{tabular}{|c|l|l|l|l|l|l|}
\hline & 2008 & \multicolumn{1}{|c|}{2009} & \multicolumn{1}{|c|}{2010} & \multicolumn{1}{|c|}{2011} & \multicolumn{1}{|c|}{2012} & \multicolumn{1}{|c|}{2013} \\
\hline General public service & 77473 & 87700 & 117308 & 141696 & 175065 & 189750 \\
\hline Public security & 24642 & 39868 & 45655 & 48570 & 59728 & 57861 \\
\hline Education & 58586 & 66834 & 82230 & 106105 & 129427 & 128797 \\
\hline Science and technology & 7491 & 9745 & 14074 & 21190 & 28881 & 31778 \\
\hline Culture, sports and media & 9739 & 13982 & 21508 & 29854 & 41349 & 41004 \\
\hline Social security and employment & 80157 & 105394 & 82583 & 120365 & 137634 & 150135 \\
\hline Health care & 29359 & 50524 & 60542 & 82761 & 96424 & 102273 \\
\hline Environmental protection & 14201 & 18266 & 26998 & 33407 & 87447 & 84162 \\
\hline Urban and rural community affairs & 24533 & 21453 & 25261 & 37046 & 71183 & 140851 \\
\hline Agriculture, forestry, water & 46055 & 71413 & 86427 & 122671 & 145258 & 175459 \\
\hline Transportation & 15079 & 23828 & 18774 & 32780 & 83207 & 88507 \\
\hline Industrial, commercial, financial affairs & 38594 & 31215 & 45206 & 23553 & 67916 & 71255 \\
\hline
\end{tabular}

Table 3. Indexes of tourism development in Huangshan City (Unit: ten thousand RMB).

\begin{tabular}{|c|l|l|l|l|l|l|}
\hline & \multicolumn{1}{|c|}{2008} & \multicolumn{1}{|c|}{2009} & \multicolumn{1}{c|}{2010} & \multicolumn{1}{|c|}{2011} & \multicolumn{1}{c|}{2012} & \multicolumn{1}{|c|}{2013} \\
\hline Total tourism income (ten thousand RMB) & 1409000 & 1681500 & 2021400 & 2510200 & 3029801 & 3145400 \\
\hline $\begin{array}{c}\text { Domestic tourism income (ten thousand } \\
\text { RMB) }\end{array}$ & 1259300 & 1535537 & 1822700 & 2260103 & 2723730 & 2843576 \\
\hline Foreign exchange earnings from tourism & 22010 & 24401 & 30100 & 38500 & 48211 & 48739 \\
\hline Domestic tourists (person-time) & 17202700 & 20348106 & 24396899 & 29230300 & 34809900 & 35720000 \\
\hline Domestic tourists (person-day) & 21719190 & 27149715 & 33278404 & 39934085 & 47585133 & 48829239 \\
\hline
\end{tabular}




\begin{tabular}{|c|l|l|l|l|l|l|}
\hline Foreign tourists (person-time) & 810405 & 877094 & 1050301 & 1313609 & 1602699 & 1605919 \\
\hline Foreign tourist (person-day) & 1160400 & 1337633 & 1673961 & 2776107 & 3386505 & 2772152 \\
\hline $\begin{array}{c}\text { Transportation, warehousing and postal } \\
\text { service }\end{array}$ & 156000 & 164200 & 170400 & 188630 & 207500 & 226961 \\
\hline Wholesale and retail & 146000 & 165322 & 188732 & 234973 & 268402 & 296961 \\
\hline Accommodation and catering & 83000 & 93900 & 105515 & 127747 & 146360 & 160886 \\
\hline Financial industry & 67000 & 73136 & 87747 & 104447 & 123544 & 148068 \\
\hline Leasing and business service & 27000 & 33900 & 38910 & 48292 & 58243 & 83600 \\
\hline Residents service and other services & 82000 & 88560 & 90668 & 108802 & 132000 & 136014 \\
\hline Culture, sports and entertainment & 42000 & 42420 & 47688 & 58121 & 65727 & 76978 \\
\hline $\begin{array}{c}\text { Public Management and Social } \\
\text { Organization }\end{array}$ & 158000 & 170939 & 178109 & 203100 & 232144 & 247000 \\
\hline
\end{tabular}

\subsection{Definition and description of factors in correlation analysis}

In correlation analysis of an abstract system, data sequences reflecting behavior characteristics of the system should be accurately selected - this process is called "selection of mapping variable reflecting system behavior". Then, relevant factors affecting main behavior of the system should also be confirmed. Generally, dependent variables constitute reference sequence $Y_{i}$, while independent variables constitute comparison sequence $X_{i}$.

\subsection{Calculation of correlation coefficients}

Based on given data of comparison and reference sequences, correlation coefficients and relational degree of comparison and reference sequences could be calculated by using the following methods and procedures. Then, the influence degree of each comparison sequence was analyzed. Analytical methods and procedures were described as follows.

(1) Initialization of raw data

Dimension or unit of each factor in raw data might be different. Therefore, the data were difficult to compare directly. Instead, they should be converted into comparable data series. There were lots of dimensionless methods for raw data. Based on researches of related scholars, the following formula was adopted:

$$
\chi_{i}^{\prime}(\kappa)=\chi_{i}^{\prime}(\kappa) / \chi_{i} .
$$

(2) Calculation of absolute difference between reference sequence and comparison sequence

$$
\Delta_{i}(\kappa)=\left|\chi_{0}^{\prime}(\kappa)-\chi_{i}^{\prime}(\kappa)\right|
$$

(3) Calculation of correlation coefficient

$$
\xi_{i}(\kappa)=\frac{\min _{i} \min _{\kappa} \Delta_{i}(\kappa)+\rho \max _{i} \max _{\kappa} \Delta_{i}(\kappa)}{\Delta_{i}(\kappa)+\rho \max _{i} \max _{\kappa} \Delta_{i}(\kappa)}
$$

where $\rho$ was resolution ratio, taking $0.5 ; \min _{i} \min _{\kappa} \Delta_{i}(\kappa)$ denotes secondary minimum difference; $\max _{i} \max _{\kappa} \Delta_{i}(\kappa)$ denotes secondary maximum difference.

(4) Calculation of relational degree

$$
\gamma_{i}=\frac{1}{n} \sum_{\kappa=1}^{n} \xi_{i}(\kappa)
$$

\subsection{Strength analysis}

In correlation analysis, correlation matrix could be constructed when there were more than one reference sequences and comparison sequences. Then, the strengths and weaknesses of elements could be analyzed through correlation matrix. For 
example, $Y_{1}, Y_{2}, \ldots \cdots Y_{s}$ was the characteristic behavior sequence of the system, while $X_{1}, X_{2}, \cdots \cdots X_{m}$ was relational behavior sequence; $Y_{i}$ and $X_{j}$ had the same length; $\gamma_{i j}(i=1,2, \ldots . . \mathrm{s} ; \mathrm{j}=1,2, \ldots . . \mathrm{m})$ was the grey relational degree of $Y_{i}$ and $X_{j}$, thus constituting the correlation matrix R: $\left(\begin{array}{cccc}\gamma_{11} & \gamma_{12} & \cdots & \gamma_{1 m} \\ \vdots & \ddots & \vdots \\ \gamma_{s 1} & \gamma_{s 2} & \cdots & \gamma_{s m}\end{array}\right)$.

Elements of the i-th line were grey relational degrees between characteristic behavior sequence of the system $Y_{i}(\mathrm{i}=$ $1,2, \ldots . . \mathrm{s})$ and relational factor sequence $x_{j}(\mathrm{j}=1,2, \ldots \ldots \mathrm{m})$. If $l$ and ${ }_{j \in}\{1,2, \ldots . . \mathrm{m}\}$, and $\gamma_{i l} \geq \gamma_{i j}$, then it indicated that system factor $X_{i}$ was superior to $X_{j}$.

\subsection{Dimensionless method}

Using the first-year value of each index to divide values of other years, then dimension could be eliminated (See Table 4).

Table 4. Dimensionless values of indexes.

\begin{tabular}{|l|c|c|c|c|c|c|}
\hline & 2008 & 2009 & 2010 & 2011 & 2012 & 2013 \\
\hline $\mathrm{X}_{1}$ & 1.0000 & 1.1320 & 1.5142 & 1.8290 & 2.2597 & 2.4492 \\
\hline $\mathrm{X}_{2}$ & 1.0000 & 1.6179 & 1.8527 & 1.9710 & 2.4238 & 2.3481 \\
\hline $\mathrm{X}_{3}$ & 1.0000 & 1.1408 & 1.4036 & 1.8111 & 2.2092 & 2.1984 \\
\hline $\mathrm{X}_{4}$ & 1.0000 & 1.3009 & 1.8788 & 2.8287 & 3.8554 & 4.2422 \\
\hline $\mathrm{X}_{5}$ & 1.0000 & 1.4357 & 2.2084 & 3.0654 & 4.2457 & 4.2103 \\
\hline $\mathrm{X}_{6}$ & 1.0000 & 1.3148 & 1.0303 & 1.5016 & 1.7171 & 1.8730 \\
\hline $\mathrm{X}_{7}$ & 1.0000 & 1.7209 & 2.0621 & 2.8189 & 3.2843 & 3.4835 \\
\hline $\mathrm{X}_{8}$ & 1.0000 & 1.2862 & 1.9011 & 2.3524 & 6.1578 & 5.9265 \\
\hline $\mathrm{X}_{9}$ & 1.0000 & 0.8745 & 1.0297 & 1.5100 & 2.9015 & 5.7413 \\
\hline $\mathrm{X}_{10}$ & 1.0000 & 1.5506 & 1.8766 & 2.6636 & 3.1540 & 3.8098 \\
\hline $\mathrm{X}_{11}$ & 1.0000 & 1.5802 & 1.2450 & 2.1739 & 5.5181 & 5.8696 \\
\hline $\mathrm{X}_{12}$ & 1.0000 & 0.8088 & 1.1713 & 0.6103 & 1.7598 & 1.8463 \\
\hline $\mathrm{Y}_{11}$ & 1.0000 & 1.1934 & 1.4346 & 1.7815 & 2.1503 & 2.2324 \\
\hline $\mathrm{Y}_{12}$ & 1.0000 & 1.2194 & 1.4474 & 1.7947 & 2.1629 & 2.2581 \\
\hline $\mathrm{Y}_{13}$ & 1.0000 & 1.1086 & 1.3676 & 1.7492 & 2.1904 & 2.2144 \\
\hline $\mathrm{Y}_{21}$ & 1.0000 & 1.1828 & 1.4182 & 1.6992 & 2.0235 & 2.0764 \\
\hline $\mathrm{Y}_{22}$ & 1.0000 & 1.2500 & 1.5322 & 1.8387 & 2.1909 & 2.2482 \\
\hline $\mathrm{Y}_{31}$ & 1.0000 & 1.0823 & 1.2960 & 1.6209 & 1.9777 & 1.9816 \\
\hline $\mathrm{Y}_{32}$ & 1.0000 & 1.1527 & 1.4426 & 2.3924 & 2.9184 & 2.3890 \\
\hline $\mathrm{Y}_{41}$ & 1.0000 & 1.0526 & 1.0923 & 1.2092 & 1.3301 & 1.4549 \\
\hline $\mathrm{Y}_{42}$ & 1.0000 & 1.1323 & 1.2927 & 1.6094 & 1.8384 & 2.0340 \\
\hline $\mathrm{Y}_{43}$ & 1.0000 & 1.1313 & 1.2713 & 1.5391 & 1.7634 & 1.9384 \\
\hline $\mathrm{Y}_{44}$ & 1.0000 & 1.0916 & 1.3097 & 1.5589 & 1.8439 & 2.2100 \\
\hline $\mathrm{Y}_{45}$ & 1.0000 & 1.2556 & 1.4411 & 1.7886 & 2.1571 & 3.0963 \\
\hline $\mathrm{Y}_{46}$ & 1.0000 & 1.0800 & 1.1057 & 1.3269 & 1.6098 & 1.6587 \\
\hline $\mathrm{Y}_{47}$ & 1.0000 & 1.0100 & 1.1354 & 1.3838 & 1.5643 & 1.8328 \\
\hline $\mathrm{Y}_{48}$ & 1.0000 & 1.0819 & 1.1273 & 1.2848 & 1.4693 & 1.5633 \\
\hline & & & & & & \\
\hline
\end{tabular}




\subsection{Results analysis and discussion}

Calculating relational degree between various factors of fiscal expenditure and tourism development, then correlation matrix R could be established as follows.

\begin{tabular}{|c|c|c|c|c|c|c|c|c|c|c|c|c|}
\hline & $\mathrm{X}_{1}$ & $\mathrm{X}_{2}$ & $\mathrm{X}_{3}$ & $X_{4}$ & $\mathrm{X}_{5}$ & $\mathrm{X}_{6}$ & $X_{7}$ & $\mathrm{X}_{8}$ & $\mathrm{X}_{9}$ & $\mathrm{X}_{10}$ & $\mathrm{X}_{11}$ & $\mathrm{X}_{12}$ \\
\hline$Y_{11}$ & 0.8635 & 0.7274 & 0.9304 & 0.6862 & 0.6462 & 0.7229 & 0.6150 & 0.7301 & 0.7865 & 0.6722 & 0.7324 & 0.7159 \\
\hline$Y_{12}$ & 0.8712 & 0.7408 & 0.9194 & 0.6911 & 0.6502 & 0.7213 & 0.6195 & 0.7334 & 0.7843 & 0.6772 & 0.7342 & 0.7083 \\
\hline$Y_{13}$ & 0.8577 & 0.7106 & 0.9439 & 0.6728 & 0.6356 & 0.7183 & 0.6049 & 0.7205 & 0.7990 & 0.6605 & 0.7309 & 0.7314 \\
\hline$Y_{21}$ & 0.7980 & 0.6713 & 0.8628 & 0.6749 & 0.6365 & 0.7678 & 0.6009 & 0.7222 & 0.7863 & 0.6577 & 0.7254 & 0.7506 \\
\hline$Y_{22}$ & 0.8908 & 0.7634 & 0.8975 & 0.7029 & 0.6591 & 0.7136 & 0.6301 & 0.7419 & 0.7765 & 0.6897 & 0.7334 & 0.6940 \\
\hline$Y_{31}$ & 0.7437 & 0.6266 & 0.7880 & 0.6521 & 0.6182 & 0.8015 & 0.5803 & 0.7058 & 0.8023 & 0.6346 & 0.7232 & 0.7971 \\
\hline$Y_{32}$ & 0.7708 & 0.6887 & 0.7366 & 0.7424 & 0.6909 & 0.6125 & 0.6969 & 0.7674 & 0.8023 & 0.7629 & 0.7521 & 0.6463 \\
\hline$Y_{41}$ & 0.5884 & 0.5068 & 0.5947 & 0.6066 & 0.5796 & 0.7485 & 0.5293 & 0.6705 & 0.7803 & 0.5793 & 0.6861 & 0.7785 \\
\hline$Y_{42}$ & 0.7452 & 0.6240 & 0.7922 & 0.6542 & 0.6201 & 0.8244 & 0.5803 & 0.7074 & 0.7956 & 0.6342 & 0.7245 & 0.8050 \\
\hline$Y_{43}$ & 0.7160 & 0.5995 & 0.7516 & 0.6473 & 0.6142 & 0.8770 & 0.5721 & 0.7021 & 0.7986 & 0.6257 & 0.7210 & 0.8375 \\
\hline $\mathrm{Y}_{44}$ & 0.7502 & 0.6442 & 0.8158 & 0.6531 & 0.6198 & 0.8011 & 0.5823 & 0.7056 & 0.8029 & 0.6346 & 0.7207 & 0.7888 \\
\hline$Y_{45}$ & 0.8102 & 0.6694 & 0.8168 & 0.7169 & 0.6760 & 0.6842 & 0.6665 & 0.7458 & 0.7938 & 0.7113 & 0.7469 & 0.6620 \\
\hline$Y_{46}$ & 0.6286 & 0.5384 & 0.6409 & 0.6202 & 0.5915 & 0.8303 & 0.5444 & 0.6805 & 0.7946 & 0.5956 & 0.6972 & 0.8224 \\
\hline$Y_{47}$ & 0.6269 & 0.5487 & 0.6457 & 0.6192 & 0.5911 & 0.8496 & 0.5460 & 0.6809 & 0.8013 & 0.5962 & 0.6993 & 0.8529 \\
\hline$Y_{48}$ & 0.6156 & 0.5255 & 0.6259 & 0.6165 & 0.5881 & 0.7835 & 0.5393 & 0.6781 & 0.7853 & 0.5904 & 0.6950 & 0.8001 \\
\hline
\end{tabular}

According to relational degree rankings between fiscal expenditure and tourism development, there was slight difference in the impact degrees of various items of local fiscal expenditure on tourism revenues, tourist person-time, tourist person-day and tourism-related industries in Huangshan City. The top five items of local fiscal expenditure showing the largest impacts were General public services, Education, Public security, Social security and employment, as well as Urban and rural community affairs; the last three items of local fiscal expenditure influencing tourism development were Culture, sports and media, Science and technology, as well as Environmental protection.

The item of local fiscal expenditure showing the largest impacts on tourism of Huangshan City was general public services. Public management and services of tourism, supported by expenditure of general public services, can achieve effective communication between different subjects in tourism market. Meanwhile, market failures of information incompletion and asymmetry can be improved, promoting effective definition and protection of property rights; a well-performed institutional environment can be formed, thereby reducing transaction costs in tourism market, with improved efficiency of tourism economy.

Local education expenditure was mainly invested in local educational administration, primary and secondary school education, as well as primary and secondary vocational education. The impact degree on tourism development of Huangshan City was not as high as general public services, indicating that education, especially for primary and secondary school education and vocational education, plays an important role in local tourism development. The reason may be that local expenditure on education provides sufficient human capital. Thus, tourism knowledge and skills with generality, professionalism and innovation can be cultivated for tourism enterprises and related departments [11]. Meanwhile, credit capital stock of tourism has been increased to promote development of tourism [12].

Public security was the third item of fiscal expenditure greatly influencing tourism development of Huangshan. It indicates that local security environment, traffic safety and other public security of tourism are also important factors affecting tourism development.

Social security and employment expenditure positioned fourth for the impacts on tourism development of Huangshan City. In the correlation between tourist person-time and development of tourism-related industries, social security and 
employment expenditure ranked in the first place. Various local expenditure and subsidies on social security, public service employment, as well as employment and vocational training promote accumulation of tourism employment, venture capital investment, as well as human capital of individuals and enterprises in Huangshan.

Expenditure on urban and rural community affairs plays an important role in promoting the development of urban and rural community planning, public infrastructure and public welfare establishments. In addition, it encourages urban and rural environmental renovation, governance of community public affairs, as well as the construction of new and beautiful countryside. Local traditions and culture can be inherited with renaissance in Huangshan, improving living spaces, public cultural space and living environment. Attraction of urban and rural tourism is enhanced, and development of local tourism accelerated thereafter.

Traffic is an essential bridge of the tourism and the infrastructural industries for tourism development. However, correlation between transportation expenditure and tourism development of Huangshan was in the sixth place. Huangshan is one of the earliest cities with tourism development. In early stage, transportation expenses were larger with more important role in tourism. However, when tourism has developed to a certain stage with continuous improvement of transportation system, marginal contribution ratio of local transportation expenditure to tourism began to showing declining trend. In addition, improvement of traffic shortened the distance between Huangshan and the Yangtze River Delta as well as other surrounding cities. The radiation Yangtze River Delta cities and other surrounding cities had promoted the development of Huangshan Tourism. However, traffic improvement also generated substitution effects of tourism demand between Huangshan and these cities. Therefore, changes of modern traffic environment had generated complex effects on tourism development.

\section{Conclusions and recommendations}

Above all, results show that the top five items of local fiscal expenditure significantly promote local tourism development are General public services, Education, Public security, Social security and employment, as well as Urban and rural community affairs. According to the results, expenditure efficiency and focuses of local government could be recognized and varied under current economic and social environment. Thus, the structure of fiscal expenditure can be further optimized, providing scientificity and rationality of decision-making in fiscal expenditure [13].

As a traditional famous tourist city, Huangshan also faces pressure and confusion of industrial upgrading and public services, as well as public administration innovation, along with changing external environment. Firstly, the combination of culture and tourism, as well as environment and tourism is not perfect enough. Secondly, new changes in traffic environment, such as high-speed rail, have brought changes of regional advantages. This has changed substitutional and complementarity relations of tourism resources and products between Huangshan and surrounding cities. Thirdly, the proportion of self-catering individual travelers has become keep increasing, thus enhancing pressures for tourism public service and public management innovation.

In the analysis of expenditure growth, Musgrave and Rostow emphasized changes of expenditure structure resulted from public need changes in different stages of economic development. Similarly, the structure of local fiscal expenditure should adapt to changes of public needs in different stages of tourism development. Government should combine its financial advantage, existing economic and resource conditions of Huangshan, as well as requirements of tourism development for tourism public demand in new stage. Meanwhile, scientificity and rationality of decision-making in fiscal expenditure should be further improved for tourism development. Government should promote industrial transformation and upgrading with industrial development goals in new stage of tourism, thus achieving fast tourism development of Huangshan and building a leading tourism city in China.

\section{Acknowledgements}

The work was supported by Anhui Province Philosophy and Social Science Planning Project (AHSKY2015D34), grant from Huangs han University Research Foundation (2014xhwh007). 


\section{References}

1. M. Thea Sinclair, Mike Stabler (Compilers), Song Haiyan, Shen Shujie (Translators), 2004. Economics of Tourism. Beijing: Higher Education Press, pp. 145-148.

2. Wang Zhidong, 2005. Empirical Research on Policy Support of Chinese Local Government to Promote Tourism Development. Dongyue Tribune, Vol 5, pp. 69-76.

3. Zheng-Xin Wang \& Lingling Pei, 2014. A systems thinking-based grey model for sustainability evaluation of urban tourism. Kybernetes, Vol. 43 Iss 3/4 pp. $462-479$.

4. Zhou, L., Dong Q, M, 2014. Research on tourism development of Xinjiang based on grey relational analysis and gravity model, Grey Systems: Theory and Application, Vol. 4 Iss 3.

5. He D, Chen K \& Zhai Y. 2012. Study on Forest Tourism and County Economy by Grey Correlation Analysis_- Taking six counties Eastern Liaoning as a case. Advanced Materials Research Vols. 347-353, pp 874-878.

6. LIU S, GAO J, \& XUE D. 2013. The evaluation of tourism festival activities impact on water environment in DongPing Forest Park based on the grey relational recognition model. Advanced Materials Research Vols. 726-731, pp 1391-1395

7. Ishikawa, $N$ \& Fukushige, M 2009. Impacts of tourism and fiscal expenditure on remote islands in Japan: a panel data analysis. Applied Economics, Vol 41, 921-928.

8. Avramescu, T,C., Baldan, C,F. 2011. Some considerations on the government involvement in tourism development through fiscal and monetary measures. Anale. Seria Ştiinţe Economice. Timişoara

9. Feliziani V., Monni S. 2013. Towards new tourism policies: The role of fiscal policy in increasing competitiveness. Tourism Review International, Vol. 16, pp. 227-237.

10. Chris Coope, John Fletcher, et al. (Compilers), Zhang Lili, Cai Liping, et al. (Translators) 2004. Tourism: Principles and Practice (Second Edition), Higher Education Press, pp. 11.

11. Hu Qinglong, 2009. Relationship between Human Capital Accumulation and Economic Growth of Huangshan Tourism-An Analytical Framework Based on Neoclassical Theory. Journal of Huangshan University, Vol 1, pp. 53-56.

12. Liu Changsheng, Jane Yufeng, Yin Hua,2009. Tourism Credit, Human Capital Development and Tourism Industry. Tourism Tribune, Vol 11, pp. 13-20.

13. Paul F.J. Eagles, 2014. Fiscal implications of moving to tourism finance for parks: Ontario Provincial Parks, Managing Leisure, 19:1, 1-17. 